\title{
A Luz ao Serviço da Humanidade - A produção DE COMBUSTÍVEIS SOLARES
}

\author{
Patrícia Raleiras* e Anders Thapper \\ Photochemistry and Molecular Science, Department of Chemistry - Ångström Laboratory, \\ Uppsala University, Suécia \\ patricia.raleiras@kemi.uu.se
}

\begin{abstract}
No âmbito das celebrações do Ano Internacional da Luz, não poderia faltar uma discussão sobre como melhor utilizar a nossa maior fonte natural de energia - a luz solar - na mudança para uma sociedade pós-combustíveis fósseis. Apresentamos aqui uma visão geral sobre a conversão directa de matérias-primas abundantes (água, dióxido de carbono) a combustíveis solares utilizando duas aproximações: a produção fotobiológica utilizando microorganismos fotossintéticos e a fotossíntese artificial.
\end{abstract}

\section{O QUE SÃO COMBUSTIVEIS SOLARES? O PROBLEMA ENERGÉTICO}

O consenso científico é claro: as mudanças climáticas são provocadas em grande parte pela actividade humana em consequência da utilização de combustíveis fósseis [1]. A natureza finita deste tipo de combustível é também inegável - mais cedo ou mais tarde, não existirá mais petróleo ou gás natural a extrair. Estes argumentos apoiam a necessária mudança de paradigma nas tecnologias de produção de energia para a sustentação do desenvolvimento humano.

O investimento na produção de energia eléctrica a partir de energia eólica e solar é visto como uma peça fundamental nesta mudança. Existe no entanto alguma confusão entre os termos “energia” e “electricidade”: muitas vezes são utilizados de forma intercambiável, dando a noção de que a solução para o problema energético passa pela instalação de equipamentos produtores de electricidade. Na realidade, a energia eléctrica é uma parte minoritária do total da energia consumida pela actividade humana à escala planetária - muito mais é utilizada sob a forma de combustíveis para, por exemplo, transporte e aquecimento. Os dados mais recentes da Agência Internacional de Energia indicam que apenas $18,1 \%$ da energia total consumida no mundo é energia eléctrica (dados de 2012) [2]; em Portugal, o número projectado para 2020 é cerca de 24,6\% [3]. Existe claramente necessidade de combustíveis que sejam possíveis de armazenar, algo difícil de fazer com a electricidade. Além da dificuldade de armazenamento, a manutenção de redes de distribuição, aliada às perdas de energia ao longo das mesmas, diminui de forma apreciável o apelo da energia eléctrica.

Não seria antes ideal produzir de forma directa um combustível armazenável a partir de fontes sustentáveis e de energia renovável?

O conceito de combustível solar surge como uma resposta viável a esta questão. Um combustível solar é produzido a partir de materiais abundantes (água, dióxido de carbono) e energia solar utilizando um processo directo. O combustível solar mais simples é o hidrogénio molecular $\left(\mathrm{H}_{2}\right)$ : a oxidação da água produz oxigénio, protões e electrões; os protões e os electrões podem ser combinados para a produção de hidrogénio. A redução química de $\mathrm{CO}_{2}$ produz também compostos com valor energético, como o metano $\left(\mathrm{CH}_{4}\right)$ (Figura 1).

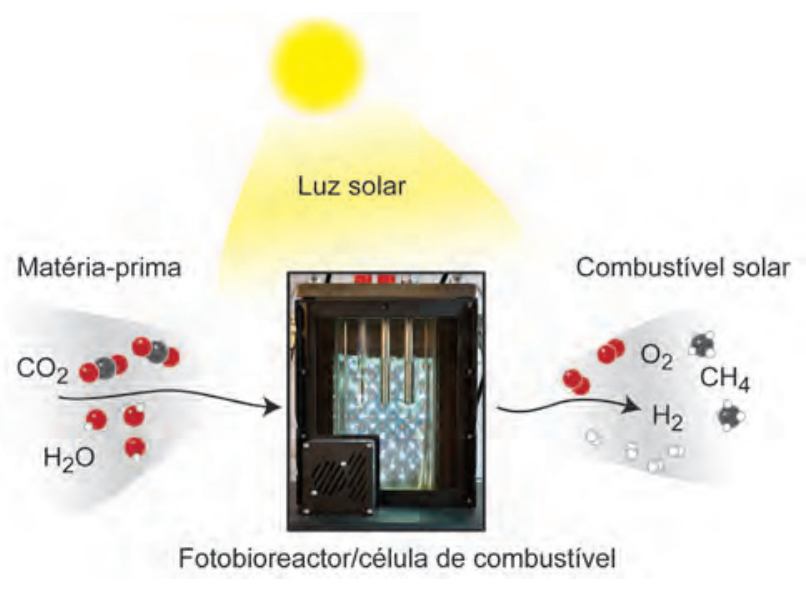

Figura 1 - Produção de combustível solar. A luz solar age como fonte de energia para a conversão directa de matérias-primas abundantes $\left(\mathrm{CO}_{2}\right.$, $\mathrm{H}_{2} \mathrm{O}$ ) a combustíveis $\left(\mathrm{H}_{2}, \mathrm{CH}_{4}\right)$. O sistema utiliza um fotobioreactor (aqui exemplificado com um dispositivo de escala laboratorial) ou uma célula de combustível utilizando fotossíntese artificial.

A utilização do termo "processo directo" aqui é importante. Não é novidade que é possível utilizar a energia solar de diversas formas, a mais conhecida sendo a utilização de painéis solares para a conversão a energia térmica ou electricidade. Estas formas de energia são contudo difíceis de armazenar e a eficiência de conversão é baixa. $\mathrm{O} \mathrm{H}_{2}$ é actualmente produzido à escala industrial em processos que exigem grandes quantidades de energia e matéria-prima fóssil. Por sua vez, a principal fonte actual de $\mathrm{CH}_{4}$ é o gás natural. Nenhuma destas vias é sustentável a longo prazo. A busca de uma fonte de energia inesgotável tem uma resposta óbvia: o sol envia-nos cerca de 122000 TW de energia, dos quais cerca de 600 TW poderiam ser aproveitáveis na prática [4]. Esta é uma quantidade de energia 
que ultrapassa largamente os cerca de 12 TW utilizados pela totalidade da actividade humana (dados de 2012) [2].

\section{FotossíNTESE - A CENTRAL ENERGÉTICA DO MUNDO}

A inspiração para a produção de combustíveis solares vem da conversão de energia solar a energia química que ocorre durante a fotossíntese. A fotossíntese é um processo no qual parte do espectro solar é absorvido e utilizado para criar um potencial suficientemente oxidante para oxidar uma molécula de água a $\mathrm{O}_{2}$. Este processo ocorre num centro multinuclear de cálcio-manganês no complexo fotossistema II. Durante a fotossíntese, não só ocorre produção de $\mathrm{O}_{2}$ como também a produção de NADPH e a criação de um potencial electroquímico que possibilita a produção de ATP. Os detalhes deste processo foram descritos numa recente edição do Química [5]. A fotossíntese é o processo que possibilita a fixação de carbono, na qual o $\mathrm{CO}_{2}$ é convertido a açúcares. Calcula-se que a fotossíntese global produz cerca de 130 TW de energia [4].

São os açúcares, ou compostos provenientes destes, que nós aproveitamos para a produção de (bio)combustíveis. Todos os biocombustíveis actualmente no mercado são, de uma forma ou outra, produto da biodegradação de biomassa; o exemplo mais conhecido é o etanol. Estes processos constituem a produção indirecta de combustíveis a partir da luz solar: a fotossíntese conduz à produção de biomassa, que pode então ser convertida a produtos úteis. Mas mesmo sendo processos industrialmente bem estabelecidos, dois problemas fundamentais subsistem. Primeiro, a fixação fotossintética de $\mathrm{CO}_{2}$ é um processo intrinsecamente pouco efectivo em termos energéticos; acrescentando-se um passo fermentativo, o rendimento de produto útil por fotão absorvido é baixo. Segundo, uma parte significativa da biomassa utilizada para produção de combustíveis ou utiliza terras aráveis, que poderiam ser utilizadas para produzir alimentos, ou coloca pressão em ecossistemas frágeis. Estes não são apenas problemas académicos, mas também sociais, políticos e éticos.

\section{Produção Fotobiológica diRECTA de combustíveis SOLARES}

A utilização de microorganismos fotossintéticos, em particular cianobactérias e algas verdes, contorna os problemas acima referidos. Ferramentas moleculares que permitem a manipulação destes organismos impulsionam o desenvolvimento de estirpes robustas que expressam as enzimas necessárias à síntese de produtos úteis. A utilização de microorganismos que utilizam a energia solar sem a necessidade de ocupar área útil para a produção de alimentos, e com necessidades mínimas de nutrição, é apelativa do ponto de vista ambiental. É por isso natural que haja um grande interesse na área da produção fotobiológica de combustíveis.

O combustível mais simples produzido por microorganismos fotossintéticos é o $\mathrm{H}_{2}$. Esforços têm sido feitos no sentido de aumentar o rendimento de produção de $\mathrm{H}_{2}$ utilizando a sobre-expressão de hidrogenases produtoras de hidrogénio ou a inactivação de hidrogenases que o oxidam [6,7]. Mais recente é a inserção de enzimas e vias metabólicas que desviam compostos provindos da fixação fotossintética de $\mathrm{CO}_{2}$ para a produção de compostos reduzidos de carbono de interesse, como o etanol, isobutanol e diversos terpenóides [8-10].

\section{CianobactérIAS E MICROALGAS VERDES - FÁBRICAS DE COM- BUSTIVEIS SOLARES}

As cianobactérias são os mais antigos organismos fotossintéticos no nosso planeta, e as grandes responsáveis pelo aparecimento do $\mathrm{O}_{2}$ na atmosfera terrestre. Existem diversas estirpes inócuas, sem capacidade de invasão ou de produção de toxinas, as quais podem ser geneticamente manipuladas. Em particular, o advento e expansão da biologia sintética têm ajudado a propulsionar a manipulação de cianobactérias na optimização da sua capacidade em acoplar a actividade fotossintética à produção directa de um combustível útil [11].

Destas, destacamos a estirpe unicelular Synechocystis PCC 6803, a primeira cianobactéria cujo genoma foi determinado [12]; e a estirpe multicelular filamentosa Nostoc punctiforme ATCC 29133, que desenvolve células especializadas denominadas heterocistos onde ocorrem condições microaerofílicas propícias à fixação de nitrogénio atmosférico $\left(\mathrm{N}_{2}\right)$ e produção de $\mathrm{H}_{2}$ (Figura 2).

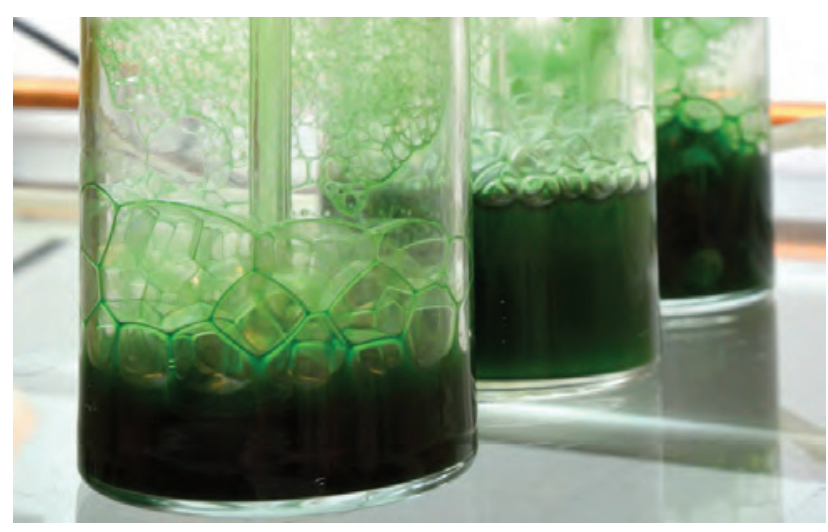

Figura 2 - Cultura de Nostoc punctiforme em frasco

Synechocystis PCC 6803 produz $\mathrm{H}_{2}$ graças à presença da enzima hidrogenase de Ni-Fe HoxEFHUY. Hidrogenases são enzimas capazes de produzir ou consumir $\mathrm{H}_{2}$, dependendo de condições fisiológicas particulares. Em Synechocystis, a hidrogenase Hox usa NADPH (provindo do catabolismo de açúcares produzidos fotossinteticamente) para produzir $\mathrm{H}_{2}$ durante as horas de escuridão; devido à sua grande sensibilidade ao $\mathrm{O}_{2}$, a Hox é rapidamente desactivada na presença de fotossíntese. Synechocystis é desta forma capaz de separar temporalmente a fotossíntese e a produção de $\mathrm{H}_{2}$. Sendo uma cianobactéria relativamente bem caracterizada e para a qual existem ferramentas moleculares bem desenvolvidas, Synechocystis é também alvo para a introdução ou alteração de vias metabólicas produtoras de compostos de carbono. Um exemplo recente consiste na inactivação da enzima esqualeno-hopeno ciclase, que resultou na acumulação intracelular de esqualeno, um 
produto com interesse comercial e potencial precursor de hidrocarbonetos de cadeia longa [13].

Em contraste, $N$. punctiforme utiliza uma estratégia envolvendo a separação espacial da produção de $\mathrm{H}_{2}$ e da fotossíntese (Figura 3). Sob condições em que a fixação de $\mathrm{N}_{2}$ é essencial para a sobrevivência do organismo, N. punctiforme diferencia algumas das células constituintes dos seus filamentos (células vegetativas) a heterocistos. O heterocisto não apresenta actividade do fotossistema II, mas mantém o fotossistema I para fotofosforilação cíclica, produzindo ATP e equivalentes redutores que podem ser utilizados pela enzima nitrogenase. O heterocisto possui um ambiente microaerofílico intracelular, propício à fixação de $\mathrm{N}_{2}$. A nitrogenase (NifDHK), enzima funcional apenas na total ausência de $\mathrm{O}_{2}$, é então capaz de reduzir $\mathrm{N}_{2}$ a amoníaco $\left(\mathrm{NH}_{3}\right)$, necessário para diversas funções celulares; é nesta reacção que existe a produção concomitante de $\mathrm{H}_{2}$. A reacção de fixação de $\mathrm{N}_{2}$ é energeticamente dispendiosa, sendo que cerca de $25 \%$ dos electrões utilizados pela hidrogenase acabam “perdidos” para o $\mathrm{H}_{2}$; por esta razão, a célula aparenta tentar recuperar estes electrões reoxidando $\mathrm{o}_{2}$ através da hidrogenase de Ni-Fe HupSL, um tipo de hidrogenase mais simples que a Hox por não depender de NADPH para a sua actividade.

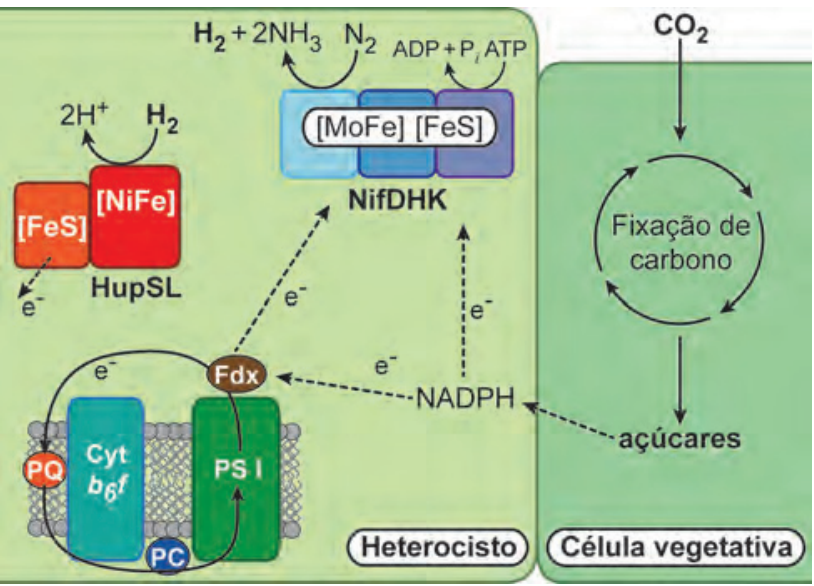

Figura 3 - Produção fotobiológica de $\mathrm{H}_{2}$ em Nostoc punctiforme. A enzima nitrogenase (NifDHK) reduz $\mathrm{H}^{+}$e $\mathrm{N}_{2}$ a $\mathrm{NH}_{3}$ e $\mathrm{H}_{2}$ no heterocisto, numa reacção dependente de ATP e poder redutor provindo do catabolismo de açúcares e da fotofosforilação cíclica. A hidrogenase HupSL reoxida $\mathrm{H}_{2}$, "reciclando" electrões utilizados pela nitrogenase

Estudos de inactivação da HupSL em N. punctiforme tornaram esta cianobactéria numa produtora líquida de $\mathrm{H}_{2}$ em condições fixadoras de $\mathrm{N}_{2}$, por ausência da reacção de reoxidação do $\mathrm{H}_{2}$ [14]. A presença de heterocistos torna estas cianobactérias valiosas como "fábricas celulares”, pois possibilitam a introdução de vias metabólicas que não toleram $\mathrm{O}_{2}$.

A microalga verde Chlamydomonas reinhardtii possui uma hidrogenase de Fe-Fe (isto é, contendo um centro bimetálico de ferro no centro activo; ver também Figura 6) que apresenta uma alta actividade produtora de $\mathrm{H}_{2}$. Neste organismo, os electrões necessários para a actividade da hidrogenase provêm ou directamente do processo fotossintético, ou indirectamente da via glicolítica após fixação fotossin- tética de $\mathrm{CO}_{2}$ [15]. Desenvolvem-se actualmente métodos para maximizar a produção de $\mathrm{H}_{2}$ a partir desta alga, em particular manipulando as condições de crescimento. A forma mais eficaz consiste na remoção de enxofre do meio de cultura, seguindo-se uma fase anaeróbia sob luz; este método promove de forma significativa a acumulação de amido, que pode então ser usado como fonte de electrões para suster a actividade da hidrogenase, junto com electrões provindos da actividade do fotossistema I [15].

\section{A FOTOSSÍNTESE ARTIFICIAL - UMA PERSPECTIVA HISTÓRICA}

A fotossíntese artificial tenta mimetizar as características mais importantes da fotossíntese natural de modo a produzir combustíveis solares num processo fotoquímico directo. Uma destas características é, naturalmente, a capacidade de utilizar a energia contida na luz solar para conduzir reacções químicas energeticamente desfavoráveis. Desta forma, a energia solar pode ser armazenada nas ligações químicas de um combustível solar. Outra característica é a utilização da água como uma das matérias-primas para o combustível solar, algo essencial para a aplicação da fotossíntese artificial à escala global. Tal como na produção fotobiológica de combustíveis solares, a cisão da molécula de água é a forma menos complicada de produzir um combustível solar utilizando fotossíntese artificial.

Um dos primeiros relatos da cisão da molécula de água induzida pela luz surgiu nos anos 70 [16], utilizando uma célula fotoelectroquímica com um ânodo do semicondutor óxido de titânio $\left(\mathrm{TiO}_{2}\right)$ e um cátodo de negro de platina. Nesta célula, o fotoânodo efectua a cisão da água a $\mathrm{O}_{2}$ e $\mathrm{H}_{2}$ quando iluminado por luz UV (Figura 4). A banda proibida (band gap) das partículas do semicondutor é suficientemente elevada e possui a magnitude correcta para poder efectuar tanto a oxidação da água como a redução de protões. Por outro lado, esta banda proibida é demasiado elevada para usar luz visível na excitação de electrões e sua injecção na banda de condução do $\mathrm{TiO}_{2}$, tornando a reacção possível apenas sob luz UV. Apesar disto, este trabalho abriu o caminho para a investigação actual em materiais usados para a captação da luz, separação de carga e catálise na fotossíntese artificial.

No início dos anos 80 do século XX, Meyer e colaboradores demonstraram que catalisadores homogéneos podem também ser utilizados para a oxidação da água [17]. O chamado blue dimer, um complexo bimetálico de ruténio, foi durante muito tempo o melhor exemplo existente, e um dos mais bem estudados, de um catalisador molecular de oxidação de água (Figura 4).

Durante os anos 90 o Consórcio Sueco para a Fotossíntese Artificial desenvolveu díades moleculares para estudar a separação de carga induzida pela luz [18]. Um exemplo consiste na díade constituída por um complexo polipiridilo de ruténio, usado como molécula fotossensível, ligado covalentemente a um complexo de manganês funcionando como doador de electrões. Na presença de um aceitador sacrificial de electrões, o complexo de manganês sofre oxi- 
dação multielectrónica induzida pela luz (Figura 4). Desenvolveram-se subsequentemente tríades em que a componente aceitadora de electrões foi incluída neste arranjo molecular.
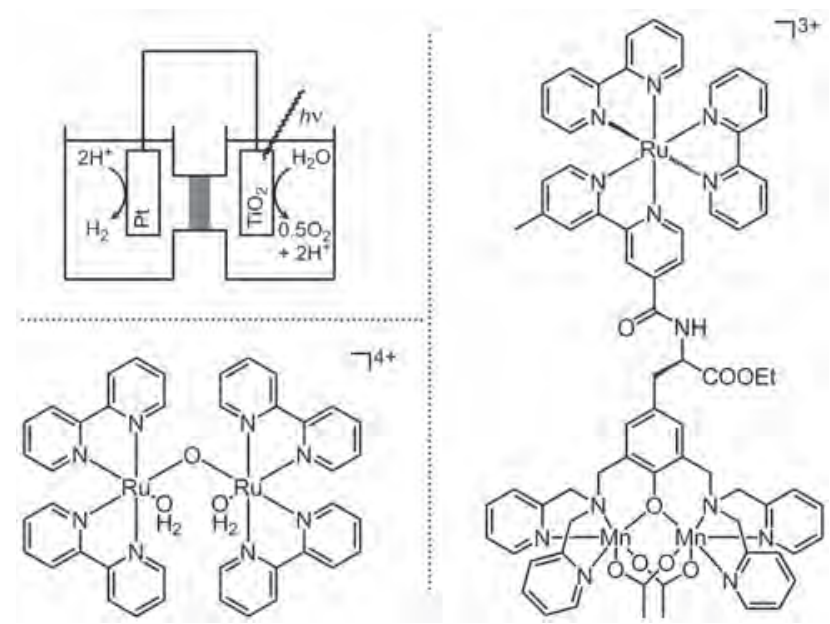

Figura 4 - Esquerda, topo: Representação esquemática da célula fotolítica de água de Fujishima e Honda. Esquerda, baixo: O blue dimer, um catalisador molecular para oxidação de água. Direita: Uma díade ruténio-manganês para separação de carga induzida pela luz

O campo de investigação na fotossíntese artificial sofreu forte expansão em anos recentes e continua a crescer rapidamente. Uma parte significativa desta expansão é proveniente do trabalho de Daniel Nocera e colaboradores sobre a utilização de óxidos de cobalto electrodepositados para oxidar água [19]; Nocera introduziu também o conceito da "folha artificial" para produção de combustíveis solares [20]. Embora este tipo de dispositivo tenha sido comunicado anteriormente, Nocera melhorou a "folha artificial” em termos de estabilidade e simplicidade de montagem [21], dois importantes aspectos a ter em conta para a sua possível comercialização.

A investigação no campo da fotossíntese artificial encontra-se actualmente num ponto em que diversos dispositivos, ou partes de dispositivos, existem à escala laboratorial. Urge agora desenvolver dispositivos para larga escala, assim como testar a usabilidade por períodos longos. Existe também espaço para melhorar o desempenho de dispositivos ao nível da investigação fundamental. Como mencionado mais abaixo, os materiais usados hoje em dia para catalisadores e para a captação de luz são frequentemente demasiado dispendiosos para possibilitar o seu emprego em larga escala.

\section{CONCEITOS PARA DISPOSITIVOS DE FOTOSSÍNTESE ARTIFICIAL}

Diversos grupos de investigação em todo o mundo exploram actualmente diferentes conceitos para a montagem de dispositivos completos [21,22]. Uma aproximação, que inclui a "folha artificial” de Nocera, baseia-se na utilização de uma célula solar multi-junção que capta luz e produz tanto um potencial de oxidação suficientemente elevado para activar um catalisador de oxidação de água como um potencial de redução suficientemente baixo para possibilitar a catálise de redução de protões (Figura 5).
Um segundo conceito utiliza semicondutores para captar luz e actuar como catalisadores, de forma semelhante ao trabalho pioneiro de Fujishima e Honda. Para poder utilizar a luz visível para a cisão da molécula de água, é potencialmente vantajoso utilizar dois semicondutores diferentes num arranjo em tandem (Figura 5). Possibilita-se assim o uso de dois semicondutores com bandas proibidas menores que possam absorver diferentes partes do espectro solar. Além disto, cada semicondutor necessita apenas de possuir os níveis de energia adequados a cada uma das reacções catalíticas (oxidação de água ou redução de protões). Os semicondutores usados incluem $\mathrm{BiVO}_{4}, \mathrm{WO}_{3}, \mathrm{Fe}_{2} \mathrm{O}_{3}, \mathrm{Ta}_{3} \mathrm{~N}_{5}$ e mais recentemente perovskitas e nitretos de carbono grafítico [22,23].

É também possível construir dispositivos híbridos, em que se acopla um semicondutor fotocatalítico a uma célula solar. Este arranjo possibilita uma configuração mais simples da célula solar (com uma ou duas junções apenas) e tem o potencial de melhorar a sua eficiência [21].

Um terceiro conceito consiste na produção de fotoeléctrodos semelhantes a células solares sensibilizadas por corante (dye-sensitized solar cells). Nesta configuração, um corante é ligado à superfície semicondutora de um eléctrodo. Para construir um fotoânodo, escolhem-se corantes e semicondutores que propiciem a injecção de electrões do estado excitado do corante ao semicondutor. Num fotocátodo, o estado excitado do corante deve, ao invés, receber electrões do semicondutor. Para possibilitar a cisão da água, os catalisadores têm também de se encontrar ligados à superfície dos eléctrodos, por co-adsorção de corantes e catalisadores ou através da ligação covalente do catalisador ao corante $[21,24]$.

Este sistema tem a vantagem de não requerer a equiparação dos níveis de energia do semicondutor com os níveis de energia da catálise. Apenas o corante (oxidado ou reduzido) precisa ser suficientemente oxidante ou redutor para activar o catalisador. Neste tipo de configuração pode ser também vantajoso construir células em tandem, usando dois corantes e dois semicondutores. Desta forma, os requisitos para cada um dos componentes podem ser menos exigentes, ao mesmo tempo que se abre a possibilidade de afinar o sistema; por outro lado, adicionam-se mais componentes ao dispositivo, aumentando a sua complexidade.

Em qualquer destes dispositivos para fotossíntese artificial, são necessários catalisadores eficientes. Nas "folhas artificiais” e nos semicondutores catalíticos têm sido predominantemente utilizados óxidos metálicos (Co ou Ir para oxidação da água), sulfuretos metálicos $\left(\mathrm{MoS}_{2}\right.$ para redução de protões), ligas metálicas (como NiMoZn para redução de protões) ou metais puros (como Pt e Pd para reacções de oxidação e redução, Ni para redução de protões) [25]. O emprego de metais raros e dispendiosos deve ser evitado tanto quanto possível para manter um baixo custo da produção de combustíveis solares, especialmente considerando-se a produção à escala global. Apesar de a platina ser um dos melhores catalisadores heterogéneos tanto para a 

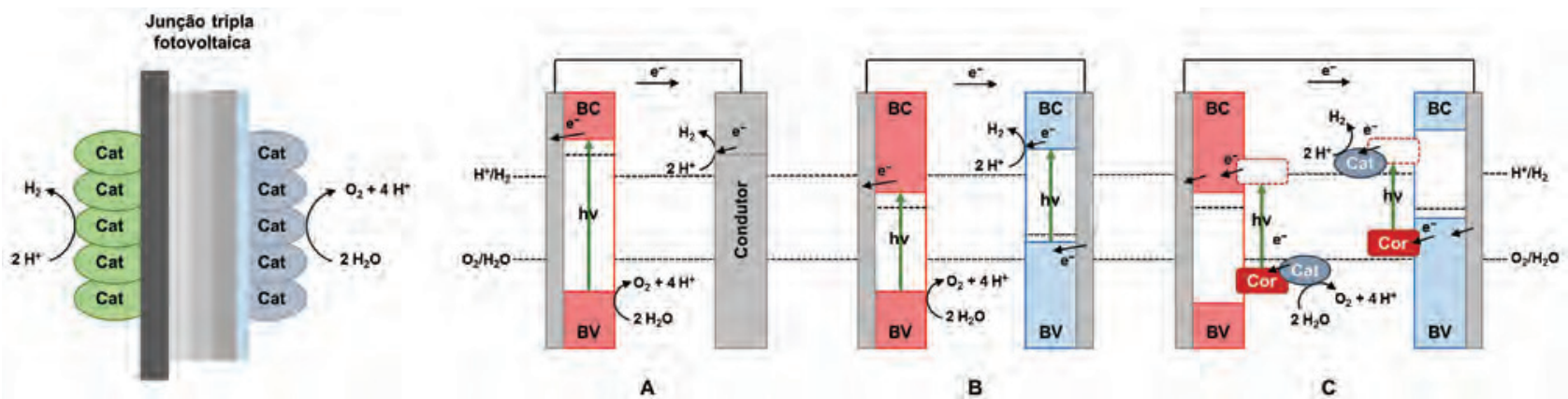

Figura 5 - Esquemas de diferentes configurações de dispositivos para fotossíntese artificial. Esquerda: A “folha artificial”. Direita: Diagramas de energia para dispositivos fotocatalíticos de cisão da água baseados em excitação em um passo único num fotoânodo (A), excitação em dois passos num fotoânodo e num fotocátodo numa configuração em tandem (B) e excitação em dois passos numa célula fotolítica sensibilizada por corante (C). BV = banda de valência, $\mathrm{BC}=$ banda de condução, Cor = corante, Cat = catalisador

redução de protões como para a oxidação da água, existe uma marcada pressão para evitar o uso deste e de outros elementos raros na construção de dispositivos completos.

Na construção de semicondutores sensibilizados por corantes, tanto o corante como o catalisador possuem normalmente uma natureza molecular; exploram-se, no entanto, também pontos quânticos (quantum dots) para este fim, em especial para a captação de luz, e nanopartículas de óxidos metálicos como catalisadores de oxidação de água. A utilização de catalisadores moleculares oferece a vantagem de se poder estudar em detalhe o mecanismo da catálise, o que por sua vez possibilita o desenvolvimento racional do catalisador. A principal desvantagem deste tipo de catalisadores tem sido, até agora, a sua menor estabilidade.

\section{Catalisadores moleculares para ReAcÇões de Fotos- SÍNTESE ARTIFICIAL}

Os catalisadores moleculares mais eficientes para a oxidação da água são complexos de ruténio e de irídio [26]; como referido acima, isto é em si problemático. Existem no entanto também complexos de metais da primeira série de transição, especialmente cobalto ou ferro [26]. Os catalisadores desenvolvidos até à data possuem um a quatro iões metálicos, desde complexos com ligandos orgânicos curtos a complexos polioxometalato (Figura 6). A existência de centros multinucleares possibilita a distribuição dos quatro equivalentes oxidantes pelos iões metálicos, embora adicione complexidade à configuração do catalisador. O único catalisador natural conhecido que oxida água, o centro CaMn do fotossistema II, possui quatro iões de manganês; todavia, tem sido até à data difícil de produzir catalisadores sintéticos de manganês.

Têm sido desenvolvidos diversos complexos biomiméticos de ferro baseados em hidrogenases de Fe-Fe para redução de protões [34]. Estes complexos são relativamente simples de sintetizar e podem possuir uma estrutura muito semelhante ao centro activo da enzima (Figura 6). No entanto, a sua actividade é muito mais baixa que a actividade da enzima. Outro tipo de moléculas utilizadas para a redução de protões e oxidação de $\mathrm{H}_{2}$ consiste em complexos de $\mathrm{Ni}$ com ligandos fosfina e amina. As fosfinas coordenam o metal e as aminas agem como base e local de ligação de protões. Existem também complexos de outros metais, tais como Co e Mo, com este tipo de actividade catalítica [34].

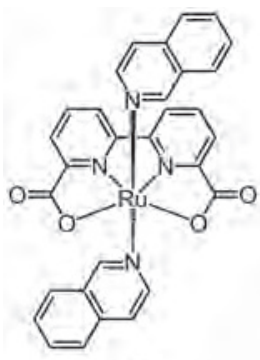

A

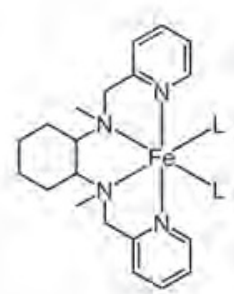

B

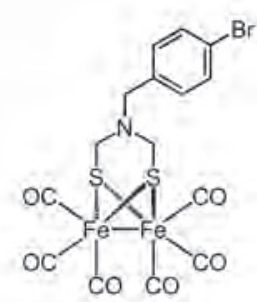

D

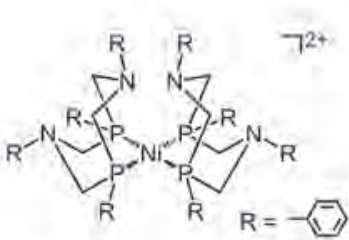

E

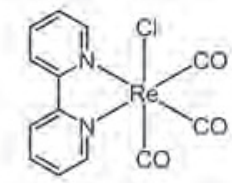

$F$

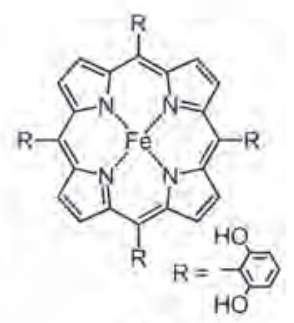

G

Figura 6 - Exemplos de catalisadores moleculares para reacções de fotossíntese artificial. A-C: Catalisadores para oxidação da água [27-29]. D-E: Catalisadores para redução de protões [30,31]. F-G: Catalisadores para redução de $\mathrm{CO}_{2}$ [32,33] 
Os catalisadores moleculares para a redução de $\mathrm{CO}_{2}$ encontram-se menos desenvolvidos que os catalisadores de redução de protões $[35,36]$. Os produtos mais comuns da redução de $\mathrm{CO}_{2}$ são o monóxido de carbono e o ácido fórmico, mas os produtos mais desejados são o metanol e, em particular, o metano. A produção fotoquímica de $\mathrm{CO}$ a partir de $\mathrm{CO}_{2}$ é relativamente interessante, devido à existência de química desenvolvida a partir de, por exemplo, CO e $\mathrm{H}_{2}$ (gás de síntese). A redução de protões é problemática para muitos dos catalisadores de redução de $\mathrm{CO}_{2}$ : o potencial necessário para reduzir $\mathrm{CO}_{2}$ é, de modo geral, suficientemente redutor para também produzir $\mathrm{H}_{2}$. É por isso necessária uma alta especificidade para a redução de $\mathrm{CO}_{2}$. Os mais bem estudados catalisadores moleculares para a redução de $\mathrm{CO}_{2}$ são complexos de rénio (Figura 6). Estes complexos são capazes tanto de captar luz como de efectuar catálise, o que os torna interessantes alvos de investigação. Complexos contendo outros metais têm sido descritos, incluindo $\mathrm{Ru}, \mathrm{Fe}, \mathrm{Mn}$ e $\mathrm{Ni}$, entre outros.

\section{CONSIDERAÇ̃̃ES FINAIS}

O interesse na produção de combustíveis solares utilizando tanto vias fotobiológicas como fotossíntese artificial tem vindo a crescer rapidamente, em particular nos últimos 10-15 anos. Um reflexo deste crescimento é o estabelecimento de uma conferência sobre combustíveis solares no prestigiado ciclo das Gordon Research Conferences [37]. O Ano Internacional da Luz vê também nascer a primeira conferência internacional exclusivamente dedicada aos combustíveis solares, ISF-1, em Uppsala, Suécia, nos finais de Abril [38].

Os conceitos para fotossíntese artificial aqui apresentados necessitam de demonstração a larga escala. Ainda não nos encontramos perto da comercialização de combustíveis solares através da fotossíntese artificial baseada nestas ou noutras configurações. Em contraste, existem interesses comerciais no presente desenvolvendo produção fotobiológica (por exemplo, Joule Unlimited nos E.U.A. [39]). O potencial para a fotossíntese artificial é no entanto talvez maior que a produção fotobiológica. O futuro dirá se esta linha de investigação corresponderá às expectativas.

\section{Agradecimentos}

Os autores gostariam de agradecer ao Consórcio Sueco para a Fotossíntese Artificial (CAP) e o apoio financeiro da Fundação Knut e Alice Wallenberg e da Agência Sueca de Energia.

\section{REFERÊNCIAS}

[1] "Climate Change 2014: Synthesis Report. Contribution of Working Groups I, II and III to the Fifth Assessment Report of the Intergovernmental Panel on Climate Change" [Core Writing Team, R.K. Pachauri and L.A. Meyer (eds.)]. IPCC, Geneva, Suíça, 151 pp. Disponível em http://www. ipcc.ch/report/ar5/syr/.

[2] “Key World Energy Statistics”. Agência Internacional de
Energia, 2014, Paris, França, 82 pp. Disponível em http:// www.iea.org/publications/freepublications/publication/ KeyWorld2014.pdf.

[3] "Energy Policies of IEA Countries. Portugal: 2009 Review”. Agência Internacional de Energia, 2009, Paris, França, 182 pp. Disponível em http://www.iea.org/publications/ freepublications/publication/Portugal2009.pdf.

[4] U. Steger, W. Achterberg, K. Blok, H. Bode, W. Frenz, C. Gather, G. Hanekamp, D. Imboden, M. Jahnke, M. Kost, R. Kurz, H. G. Nutzinger, T. Ziesemer, Terminological and Conceptional Foundations, in "Sustainable Development and Innovation in the Energy Sector", Springer-Verlag, Berlin Heidelberg, Alemanha, 2005, 32-33

[5] J.J.G. Moura, L.B. Maia, S.R. Pauleta, I. Moura, QUÍMICA 136 (2015) 17-19

[6] C. Schwarz, Z. Poss, D. Hoffmann, J. Appel, Adv. Exp. Med. Biol. 675 (2010) 305-348

[7] P. Tamagnini, E. Leitão, P. Oliveira, D. Ferreira, F. Pinto, D.J. Harris, T. Heidorn, P. Lindblad, FEMS Microbiol. Rev. 31 (2007) 692-720

[8] M. Deng, J.R. Coleman, Appl. Environ. Microbiol. 65 (1999) 523-528

[9] B. Pattanaik, P. Lindberg, Life 5 (2015) 269-293

[10] D.C. Ducat, J.C. Way, P.A. Silver, Trends Biotechnol. 29 (2011) 95-103

[11] T. Heidorn, D. Camsund, H.H. Huang, P. Lindberg, P. Oliveira, K. Stensjö, P. Lindblad, Methods Enzymol. 497 (2011) 539-79

[12] T. Kaneko, S. Sato, H. Kotani, DNA Res. 3 (1996) 185-209

[13] E. Englund, B. Pattanaik, S.J. Ubhayasekera, K. Stensjö, J. Bergquist, P. Lindberg, PLoS One 9 (2014) e90270

[14] P. Lindberg, K. Schütz, T. Happe, P. Lindblad, Int. J. Hyd. Energy 27 (2002) 1291-1296

[15] G. Torzillo, A. Scoma, C. Faraloni, L. Giannelli, Crit. Rev. Biotechnol. (2014) 1-12

[16] A. Fujishima, K. Honda, Nature 238 (1972) 37-38

[17] S.W. Gersten, G.J. Samuels, T.J. Meyer, J. Am. Chem. Soc. 104 (1982) 4029-4030

[18] A. Magnuson, M. Anderlund, O. Johansson, P. Lindblad, R. Lomoth, T. Polivka, S. Ott, K. Stensjö, S. Styring, V. Sundström, L. Hammarström, Acc. Chem. Res. 42 (2009) 1899-1909

[19] M.W. Kanan, D.G. Nocera, Science 321 (2008) 1072-1075

[20] D.G. Nocera, Acc. Chem. Res. 45 (2012) 767-776

[21] K.S. Joya, Y.F. Joya, K. Ocakoglu, R. van de Krol, Angew. Chem. Int. Ed. Engl. 52 (2013) 10426-10437

[22] T. Hisatomi, J. Kubota, K. Domen, Chem. Soc. Rev. 43 (2014) 7520-7535

[23] Y. Gong, M. Li, Y. Wang, ChemSusChem 8 (2015) 931-946

[24] S. Styring, Faraday Discuss. 155 (2012) 357-376

[25] S. Das, W.M.A. Wan Daud, RSC Advances 4 (2014) 20856

[26] M.D. Kärkäs, O. Verho, E.V. Johnston, B. Åkermark, Chem. Rev. 114 (2014) 11863-12001 
[27] L. Duan, F. Bozoglian, S. Mandal, B. Stewart, T. Privalov, A. Llobet, L. Sun, Nat. Chem. 4 (2012) 418-423

[28] J. Lloret-Fillol, Z. Codolà, I. Garcia-Bosch, L. Gómez, J.J. Pla, M. Costas, Nat. Chem. 3 (2011) 807-813

[29] H.Y. Wang, E. Mijangos, S. Ott, A. Thapper, Angew. Chem. Int. Ed. Engl. 53 (2014) 14499-14502

[30] S. Ott, M. Kritikos, B. Åkermark, L. Sun, R. Lomoth, Angew. Chem. Int. Ed. Engl. 43 (2004) 1006-1009

[31] A.D. Wilson, R.H. Newell, M.J. McNevin, J.T. Muckerman, M. Rakowski DuBois, D.L. DuBois, J. Am. Chem. Soc. 128 (2006) 358-366

[32] J. Hawecker, J.-M. Lehn, R. Ziessel, J. Chem. Soc., Chem. Commun. (1983) 536

[33] C. Costentin, S. Drouet, M. Robert, J.M. Saveant, Science 338 (2012) 90-94
[34] W.T. Eckenhoff, R. Eisenberg, Dalton Trans. 41 (2012) 13004-13021

[35] A.J. Morris, G.J. Meyer, E. Fujita, Acc. Chem. Res. 42 (2009) 1983-1994

[36] J. Qiao, Y. Liu, F. Hong, J. Zhang, Chem. Soc. Rev. 43 (2014) 631-675

[37] Gordon Research Conferences - Conference portfolio (Renewable Energy: Solar Fuels): https://www.grc.org/conferences.aspx?id=0000556 (Gordon Research Conferences, acedido a 09/04/2015)

[38] Solar Fuels Conference 2015: http://www.solarfuel.se/ meetings/ (Swedish Consortium for Artificial Photosynthesis, acedido a 09/04/2015)

[39] Joule Unlimited: http://www.jouleunlimited.com/ (Joule Unlimited, acedido a 09/04/2015)

\section{Actualidades Científicas}

\section{LIGAÇÃO QUÍMICA NÃO USUAL ENTRE ELEMENTOS DO GRUPO 12}

Investigadores no Reino Unido obtiveram o complexo trimetálico $\left\{\left({ }^{A r}{ }^{\prime} \mathrm{NacNac}\right) \mathrm{Zn}\right\}_{2} \mathrm{Hg}$ ( ${ }^{\mathrm{Ar}} \mathrm{NacNac}=\mathrm{HC}\{\mathrm{C}(\mathrm{Me}) \mathrm{N}(2,6-$ $\left.\left.-\mathrm{C}_{6} \mathrm{H}_{3}{ }^{\mathrm{P}} \mathrm{Pr}_{2}\right)\right\}_{2}$ ) que possui uma unidade $\mathrm{Zn}-\mathrm{Hg}-\mathrm{Zn}$, o primeiro exemplo de catenação envolvendo metais diferentes exclusivamente do grupo 12.

O composto foi obtido pelo grupo de Philip Moutford da Universidade de Oxford, através da redução de ( ${ }^{\text {Ar'NacNac) }}$ ZnI com amálgama de mercúrio/zinco. Cálculos teóricos sugerem que a unidade Zn-Hg-Zn é descrita mais correctamente como $\mathrm{Zn}(\mathrm{I})-\mathrm{Hg}(0)-\mathrm{Zn}(\mathrm{I})$, tratando-se também de um caso raro em que o zinco se encontra no estado de oxidação formal +1. A equipa explorou também a química deste composto promovendo reacções com $\mathrm{I}_{2}, \mathrm{FpI}_{\mathrm{ou}} \mathrm{Fp}_{2}(\mathrm{Fp}=$ $\mathrm{CpFe}(\mathrm{CO})_{2}$ ) tendo obtido ( $\left.{ }^{A}{ }^{\prime} \mathrm{NacNac}\right) \mathrm{ZnX}(\mathrm{X}=\mathrm{I}$, Fp) e Hg. Estudos adicionais estão a ser realizados neste composto e seus análogos intermetálicos por esta equipa de investigadores.

(adaptado de "Group 12 members unite in unusual bonding situation, http://www.rsc.org/chemistryworld/2015/03/ group-12-zinc-mercury-unusual-bonding-situation”; M.P. Blake, N. Kaltsoyannis, P. Mountford. Chem. Commun., 51 (2015) 5743-5746 - DOI: 10.1039/C5CC00637F)

Paulo Mendes (pjgm@uevora.pt)

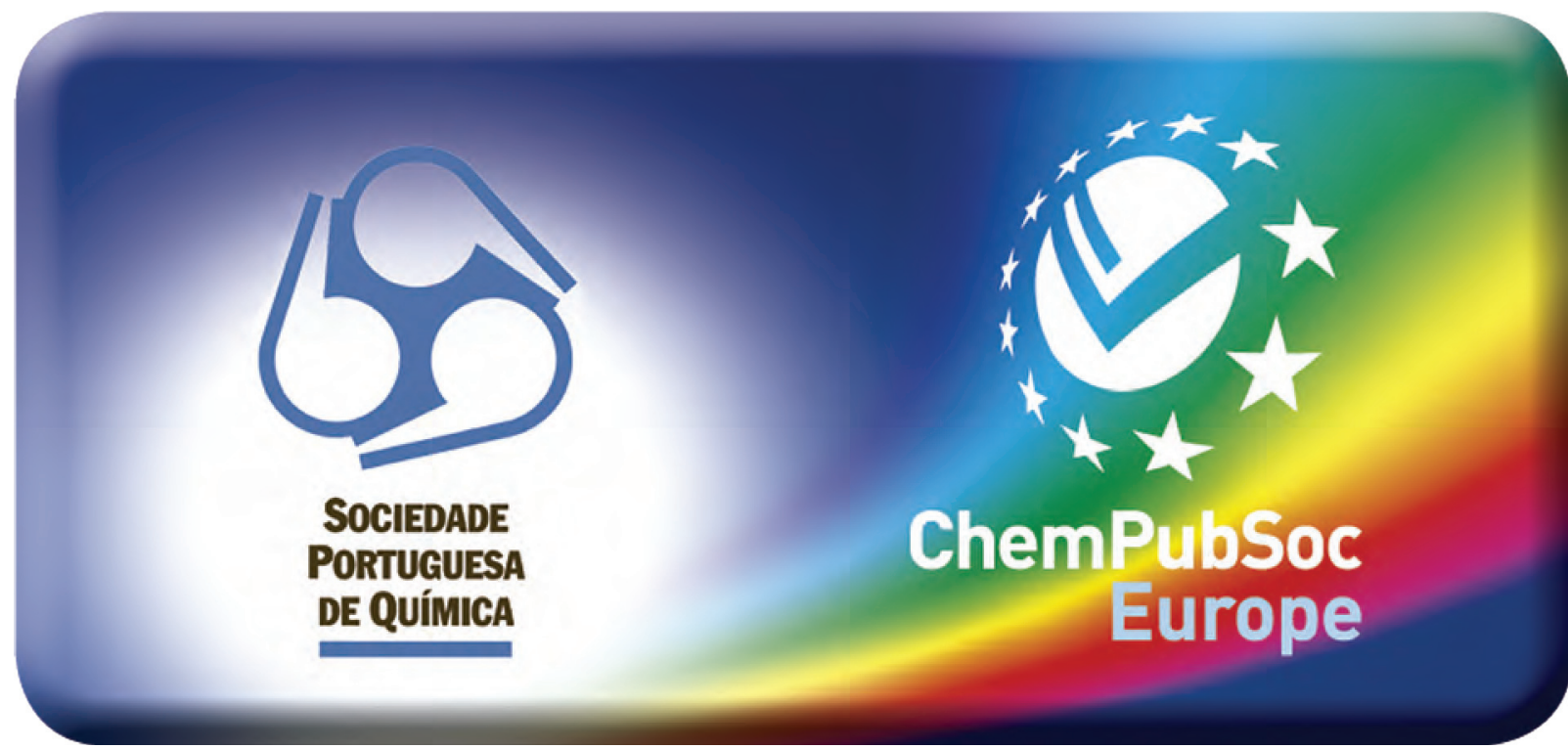




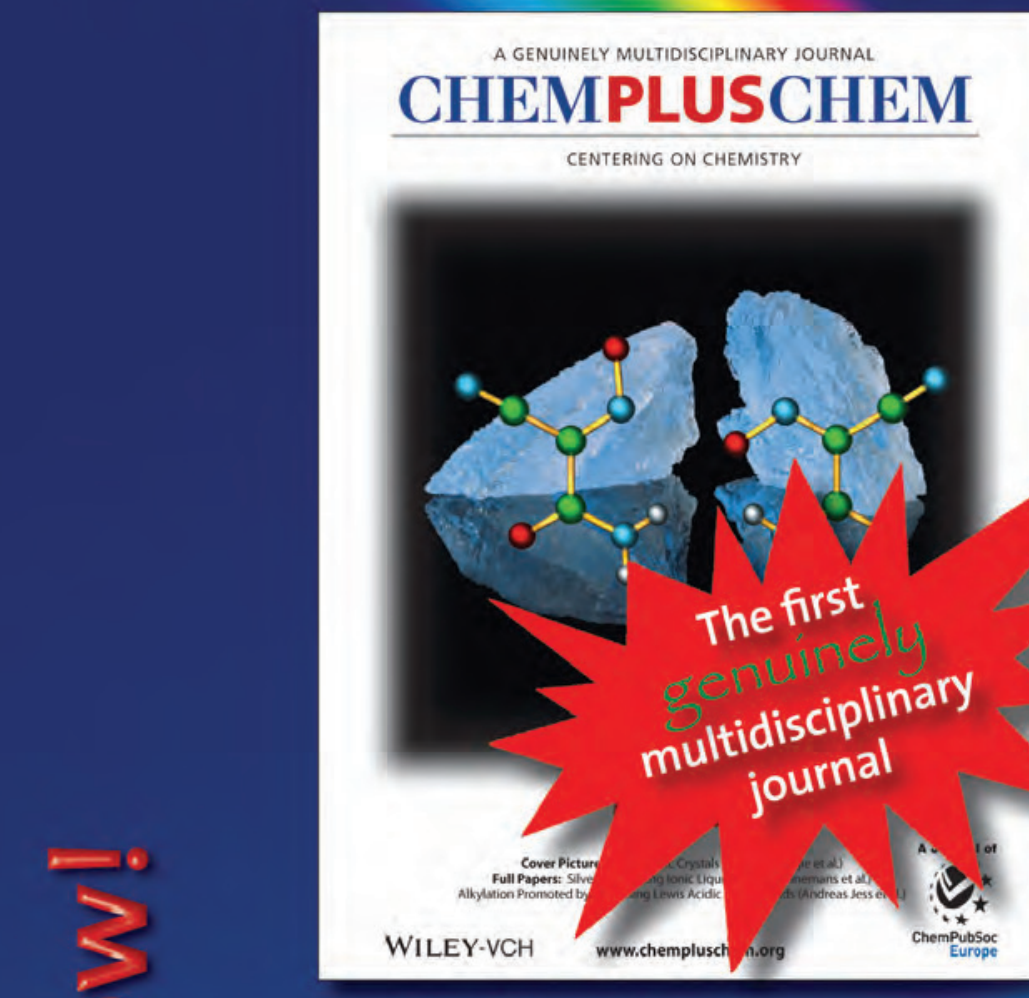

\section{www.chempluschem.org}

Editorial Team

Editor: Neville Compton

Deputy Editor: Marisa Spiniello

ChemPlusChem presents multidisciplinary research in a variety of formats:

Minireviews

Reviews

Full Papers

Communications

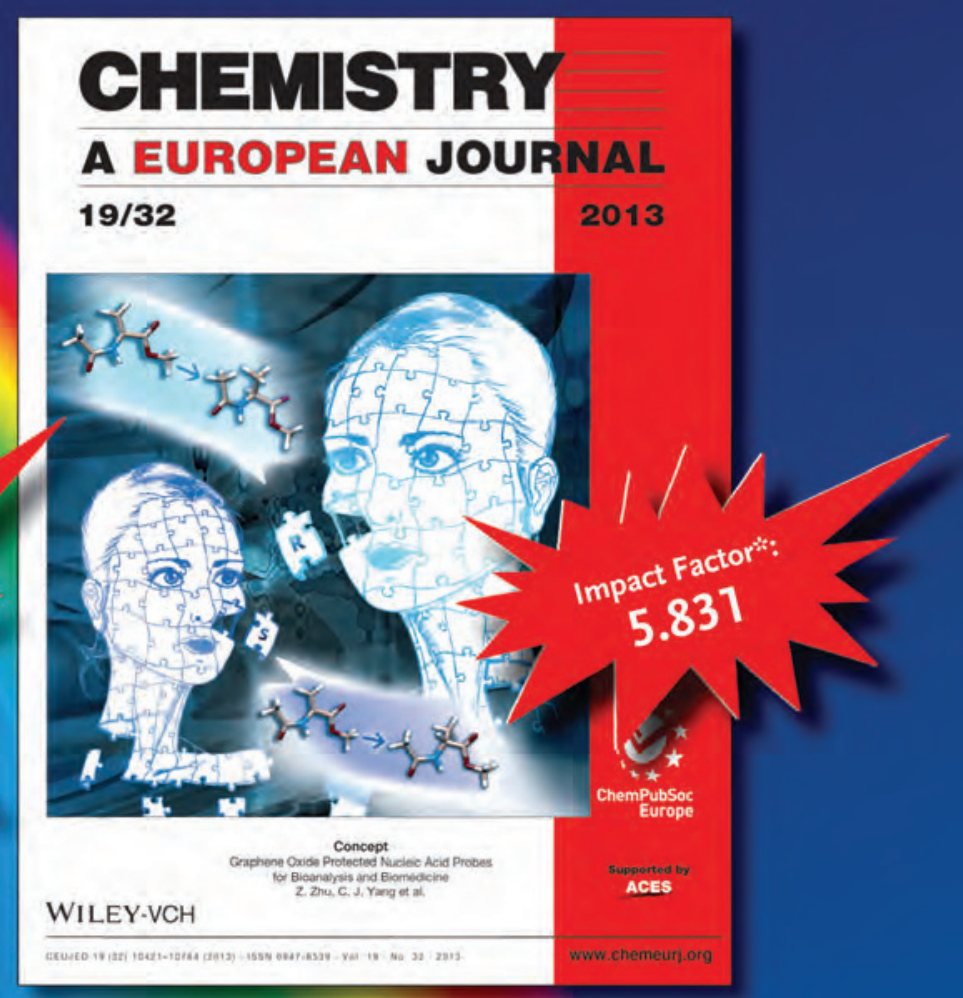

www.chemeurj.org

Editorial Team

Editor: Neville Compton

Deputy Editors: Anne Deveson and Elisabeth Roedern

2013 Release of Journal Citation Reports"

Source:Thomson Reuters, 2012 Citation Data

ChemPlusChem succeeds the

Collection of Czechoslovak Chemical

Communications

Articles in ChemPlusChem cover at least two different field of chemistry or one of chemistry and one of another scientific discipline:

general chemistry

biotechnology

organic chemistry

inorganic chemistry

physical chemistry

macromolecular chemistry analytical chemistry

biological chemistry

organometallic chemistry

polymer chemistry

computational chemistry

environmental chemistry materials chemistry

nanochemistry

medicinal chemistry

electrochemistry

catalysis

coordination chemistry

manuseript press 